\title{
Ultrasonic Scission of Deoxyribonucleic Acid in Aqueous Solution IV. Circular Dichroism of Sonicated and Unsonicated DNA in Water-Alcohol Mixed Solvents
}

\author{
Kiyohiro Fukudome, Kiwamu Yamaoka, ${ }^{*}$ and Mutsuhito Yamaguchi \\ Faculty of Science, Hiroshima University, Higashisenda-machi, \\ Naka-ku, Hiroshima 730, Japan
}

(Received April 2, 1990)

\begin{abstract}
The circular dichroic (CD) spectra of calf thymus deoxyribonucleic acid (hDNA) and the sonicated fragment (sDNA) with weight-average molecular weights of $580 \times 10^{4}$ and $14.2 \times 10^{4}$, respectively, were measured in the $220-320 \mathrm{~nm}$ wavelength region at $15^{\circ} \mathrm{C}$ in water-alcohol mixed solvents with an ionic strength of $0.4 \times 10^{-3}$. The effect of ionic valence on $\mathrm{CD}$ spectra was examined with sodium or magnesium ions as the counterion and $\mathrm{NaH}_{2} \mathrm{PO}_{4} / \mathrm{Na}_{2} \mathrm{HPO}_{4}$ or $\mathrm{Mg}\left(\mathrm{CH}_{3} \mathrm{COO}\right)_{2} / \mathrm{CH}_{3} \mathrm{COOH}$ as the buffer reagent. The $\mathrm{CD}$ spectra of both hDNA and sDNA with the $\mathrm{Na}^{+}$counterion showed a B-form pattern in $0-70 \mathrm{vol} \%$ ethanol and transformed to an A-form profile in $72-90 \mathrm{vol} \%$, the spectral change of hDNA being more cooperative than that of sDNA. Trifluoroethanol (TFE) induced changes in the CD spectra of sDNA as ethanol. In the case of the $\mathrm{Mg}^{2+}$ counterion, the CD spectra of $\mathrm{h}$ - and sDNA revealed the B-form pattern between 0 and $40 \%$ ethanol. A further addition of ethanol induced another spectral change, but fibrous precipitates appeared above $56 \%$ ethanol. From circular dichroic point of view, both hDNA and sDNA behave identically toward counterion, ethanol and TFE, their secondary structure probably remaining much the same.
\end{abstract}

KEY WORDS Deoxyribonucleic Acid / Ultrasonic Scission / Melting / Circular Dichroism / B-A Structural Transition / Ethanol / Trifluoroethanol /

While the secondary structure of crystalline DNA has been unraveled with developments in synthesis and crystallization of oligomeric DNA,${ }^{1-3}$ the conformation of polymeric DNA in solution remains still unresolved. The circular dichroism (CD) technique has been used to study the thermal stability and the effects of counterion, ionic strength, organic solvent, etc., on the higher-order structure of nucleic acids. ${ }^{4-22}$ Ivanov et al., for example, reported that the addition of excess salt or methanol induces a structural transition from $\mathrm{B}$ to $\mathrm{C}$ form but the addition of ethanol induces the $\mathrm{B}$ to $\mathrm{A}$ transition. ${ }^{4}$ This transition has also been studied by other techniques, e.g., X-ray diffraction, ${ }^{23,24}$ Raman scattering, ${ }^{25}$ nuclear magnetic resonance, ${ }^{26}$ and electric linear dichroism. ${ }^{27-29}$ Although the $\mathrm{CD}$ is a sensitive means that can detect many subtle changes, it is actually an empirical one to identify the secondary structure of DNA in solution.

The helical structure of DNA is defined by the axial translation per base pair, the tilt, roll and twist angles of the base pair plane, the pitch of helix, the sugar puckering, etc. ${ }^{3}$ If the absolute molecular weight and the chain length of unperturbed (completely straight) DNA helix are available, those structural parameters may be detemined mostly by viscosity and light scattering or their combination with $\mathrm{CD}$, or more preferably with the pulsed electrooptic techniques. ${ }^{27-29}$ The overall conformation of

\footnotetext{
* To whom correspondence should be addressed.
} 
high-molecular-weight DNA (hDNA) is, however, complex because of chain flexibility, depending on the valence of counterion, salt concentration, and other solution properties. Hence, the DNA molecule should be in a rigid rodlike or ellipsoidal shape for a simpler interpretation of the hydrodynamic results.

We have established a method of preparing low-molecular-weight DNA samples with the narrow molecular weight distribution, in large quantities, by sonication..$^{30-32}$ In this work, we report the effect of the chain length of the DNA helix on the CD spectra which sensitively reflect environmental changes. We clarify the relationship between the $C D$ spectra and the alcohol content for hDNA and its sonicated fragment (sDNA) with two objectives: (1) if the DNA length and counterion species affect the ethanol-induced transition and (2) whether trifluoroethanol, a far-UV transparent alcohol, ${ }^{33}$ induces the $\mathrm{CD}$ spectral change as ethanol. In order to avoid the problem, which would arise from molecular flexibility even for short sDNA, ${ }^{32}$ we chose an extremely low ionic condition to straighten out the chain backbone by electrostatic repulsion.

\section{EXPERIMENTAL}

Materials and Preparation of DNA Solution

The characterization of a high-molecularweight calf thymus DNA (hDNA) sample (Worthington Biochemical Corp., U.S.A.) and a sonicated and fractionated DNA (sDNA) sample was reported in previous papers. ${ }^{30-32}$ The weight-average molecular weights used in this work were $580 \times 10^{4}$ for hDNA and $14.2 \times 10^{4}$ for sDNA. Trifluoroethanol (Aldrich Chemical Co., U.S.A.) was used without further purification and all other chemicals were of reagent grade.

Stock hDNA and sDNA solutions (the concentration of DNA ca. $0.5 \mathrm{mg} \mathrm{ml}^{-1}$ in $0.2 \mathrm{M}$ $\mathrm{NaCl}$ ) were prepared as described previously. ${ }^{30,34}$ Each solution was dialyzed for $72 \mathrm{~h}$ at $4^{\circ} \mathrm{C}$ against a buffer solution ( $\mathrm{pH}$ ca. 7 ), whose composition was either $\mathrm{NaH}_{2} \mathrm{PO}_{4} / \mathrm{Na}_{2} \mathrm{HPO}_{4}$ or $\mathrm{Mg}\left(\mathrm{CH}_{3} \mathrm{COO}\right)_{2} / \mathrm{CH}_{3} \mathrm{COOH}$ at an ionic strength of $4 \times 10^{-3}$; totally 8 liters of the buffer solution were changed. To prepare a DNA solution for CD measurements, distilled water and then alcohol (ethanol or trifluoroethanol) were added dropwise to the dialyzed solution which was stirred gently at $c a .0^{\circ} \mathrm{C}$ (the content of alcohol was expressed in vol\%). The final solution was stood at $4^{\circ} \mathrm{C}$ for $5-24 \mathrm{~h}$ prior to use for CD measurements. No DNA precipitate appeared in the solutions which contained less than $90 \%$ ethanol for NaDNA or less than $56 \%$ ethanol for MgDNA.

\section{Methods and Measurements}

Absorption Spectra and Melting Profile. The absorption spectra of DNA in wateralcohol mixtures were measured in 1-cm long quartz cells on a Shimadzu UV-250 spectrophotometer. The temperature of a sample solution was varied from 10 to $80^{\circ} \mathrm{C}$, by circulating temperature-regulated water. The following characteristic parameters were evaluated from the measured melting profile at $260 \mathrm{~nm}$ : the fractional absorbance change, $f$, defined as $\left(A-A_{\mathrm{n}}\right) /\left(A_{\mathrm{d}}-A_{\mathrm{n}}\right)$, where $A_{\mathrm{n}}$ is the absorbance of a native DNA sample, $A_{\mathrm{d}}$ is the absorbance of heat-denatured DNA sample, and $A$ is the absorbance at a given temperature; the hyperchromicity, $H$, defined as $\left(A_{\mathrm{d}}-A_{\mathrm{n}}\right) / A_{\mathrm{n}}$; the melting temperature, $T_{\mathrm{m}}$, defined as the temperature at $f=0.5$; the breadth of metling transition, $\Delta T$, defined as the difference in temperatures where $f=0.9$ and 0.1 .

Circular Dichroism. The ellipticity, $\psi$, of a DNA solution was measured at $15^{\circ} \mathrm{C}$ in a $1-\mathrm{cm}$ long quartz cell on a DICHROGRAPH MARK III-J spectropolarimeter (Union Gikken Co.) in the $220-320 \mathrm{~nm}$ region. The CD data were accumulated, averaged, and then recorded on a microcomputer. The molar dichroic absorption, $\Delta \varepsilon$, in $\mathrm{dm}^{3} \mathrm{~mol}^{-1} \mathrm{~cm}^{-1}$ is related to $\psi$ as

$$
\Delta \varepsilon=\varepsilon_{\mathrm{L}}-\varepsilon_{\mathrm{R}}=(4 \pi / 180)(1 / \ln 10)(\psi / c d)
$$


where $\varepsilon_{\mathbf{L}}$ and $\varepsilon_{\mathbf{R}}$ are the molar absorption coefficients for the left and right circularlypolarized light beams, $c$ is the molar concentration of DNA in $\mathrm{moldm}^{-3}$, expressed in terms of mononucleotide unit, and $d$ is the optical pathlength in $\mathrm{cm}$.

\section{RESULTS AND DISCUSSION}

\section{Thermal Stability of Double-Stranded DNA}

Effect of Counterion on Melting. Figure 1a shows the melting curves of sDNA and hDNA in aqueous solutions cotaining the counterion $\mathrm{Na}^{+}$or $\mathrm{Mg}^{2+}$. The fractional absorbance change is plotted against temperature. The $f$-value cooperatively increases with an increase in temperature, indicating that DNA remains as the double-stranded helix at $15^{\circ} \mathrm{C}$, where the CD spectra were measured. The melting temperature $T_{\mathrm{m}}$ is high at $83^{\circ} \mathrm{C}$ for $\mathrm{Mg}$-hDNA but low at $41^{\circ} \mathrm{C}$ for Na-hDNA under the same ionic strength $\left(0.4 \times 10^{-3}\right)$, whereas the $\Delta T$ values are $10^{\circ} \mathrm{C}$ and $26^{\circ} \mathrm{C}$; thus, MgDNA is thermally denatured more cooperatively than NaDNA. Clearly $\mathrm{Mg}^{2+}$ ions stabilize the helical structure more effectively than $\mathrm{Na}^{+}$, probably because of the neutralization of negative charges on DNA, which results from the electrostatic attractive force by positively charged counterions. ${ }^{35}$ It is surprising indeed that $H$-, $T_{\mathrm{m}}$-, and $\Delta T$-values were all affected only slightly by the difference in molecular weights $\left(580 \times 10^{4}\right.$ versus $14.2 \times 10^{4}$ !) of hDNA and sDNA irrespective of the $\mathrm{Na}^{+}$or $\mathrm{Mg}^{2+}$ counterion. These results indicate that the ultrasonic irradiation simply cuts the hDNA helix laterally to yield shorter fragments but does not denature them; sDNA is optically indistinguishable from hDNA.

Effect of Added Ethanol on Melting. Figure $1 \mathrm{~b}$ shows the melting profile of NaDNA in water-ethanol mixtures. (The melting curves of MgDNA in water-ethanol mixtures could not be measured at elevated temperatures because of the scattered light by DNA precipitates.) The sDNA helix in $\mathrm{NaCl}$ solution melts

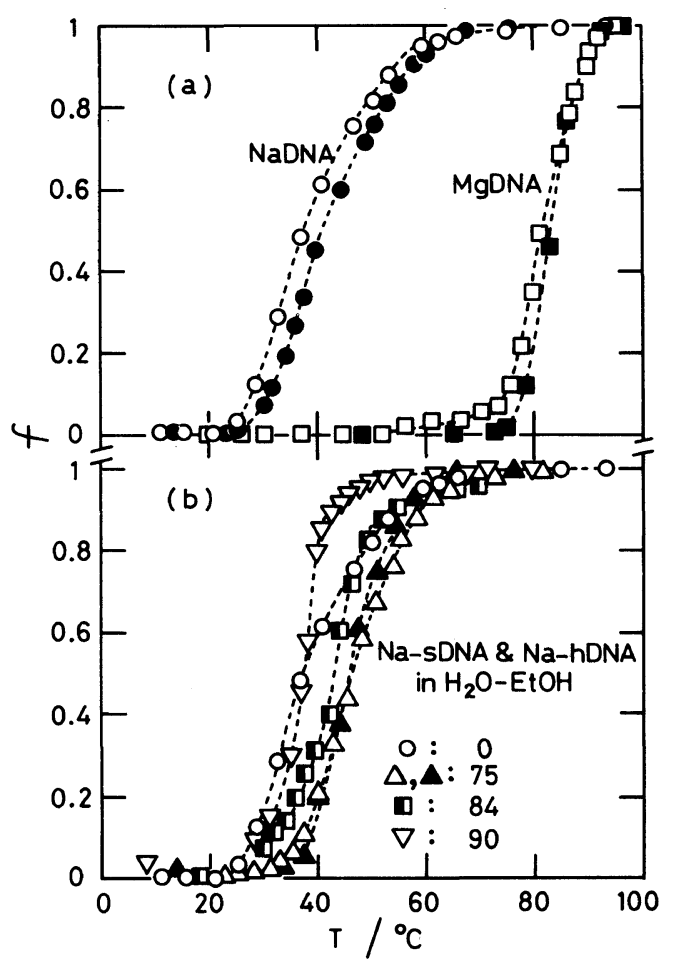

Figure 1. (a) Melting profiles of hDNA and sDNA in aqueous salt solution and (b) those of SDNA in the water-ethanol mixed solvent system. The fraction of absorbance change at $260 \mathrm{~nm}, f$, was plotted against temperature, $T$. The ionic strength was kept at $0.4 \times 10^{-3}$ with $\mathrm{Mg}\left(\mathrm{CH}_{3} \mathrm{COO}\right)_{2} / \mathrm{CH}_{3} \mathrm{COOH}(\square, \square)$ or $\mathrm{NaH}_{2} \mathrm{PO}_{4} /$ $\mathrm{Na}_{2} \mathrm{HPO}_{4}(\mathrm{O}, \mathrm{O})$. In (a) hDNA sample: $\mathrm{O},(H=41 \%$, $\left.T_{\mathrm{m}}=41^{\circ} \mathrm{C}, \Delta T=26^{\circ} \mathrm{C}\right) ; \square,\left(H=41 \%, T_{\mathrm{m}}=83^{\circ} \mathrm{C}, \Delta T=\right.$ $\left.10^{\circ} \mathrm{C}\right)$. In (a) sDNA sample: $\mathrm{O},\left(H=36 \%, T_{\mathrm{m}}=38^{\circ} \mathrm{C}\right.$, $\left.\Delta T=27^{\circ} \mathrm{C}\right) ; \square,\left(H=41 \%, T_{\mathrm{m}}=82^{\circ} \mathrm{C}, \Delta T=13^{\circ} \mathrm{C}\right)$. In (b) hDNA sample: $\boldsymbol{\Delta},\left(H=47 \%, T_{\mathrm{m}}=46^{\circ} \mathrm{C}, \Delta T=13^{\circ} \mathrm{C}\right)$. In (b) sDMA sample: $\bigcirc,\left(H=36 \%, T_{\mathrm{m}}=38^{\circ} \mathrm{C}, \Delta T=27^{\circ} \mathrm{C}\right)$; $\triangle,\left(H=44 \%, T_{\mathrm{m}}=46^{\circ} \mathrm{C}, \Delta T=22^{\circ} \mathrm{C}\right) ; \mathrm{D}, \quad(H=21 \%$, $\left.T_{\mathrm{m}}=43^{\circ} \mathrm{C}, \Delta T=24^{\circ} \mathrm{C}\right) ; \nabla,\left(H=32 \%, T_{\mathrm{m}}=38^{\circ} \mathrm{C}, \Delta T=\right.$ $\left.14^{\circ} \mathrm{C}\right)$. Numerals in (b) indicate the ethanol content in vol\%.

cooperatively in the $0-90 \%$ ethanol range with a narrower $\Delta T$ value at higher alcohol content, but a double-helical structure is obviously maintained at $15^{\circ} \mathrm{C}$. In the $0-75 \%$ ethanol range, $T_{\mathrm{m}}$ increases with increasing alcohol content. Values of $T_{\mathrm{m}}$ reach a maximum $\left(46^{\circ} \mathrm{C}\right)$ at $75 \%$ ethanol but decrease gradually thereafter. The factors involved in stabilizing the DNA structure are the hydrogen 
bond between bases, the shielding of electrostatic repulsion between charged phosphate groups by counterions, the hydrophobic bonding (base stacking), and the hydrated sheath by water molecules. The shielding may be increased with a decrease in the dielectric constant of the solvent, which may promote the charge neutralization by counterions, the helical structure being stabilized up to $75 \%$ ethanol, whereas the decrease in $T_{\mathrm{m}}$ above $75 \%$ may be caused by the collapse of the sheath, i.e., the release of hydrated water from the DNA grooves. The fact that value of $\Delta T$ decreases, i.e., the melting profile sharpens, with the increase in the alcohol content suggests the increase in the transitional cooperativity.

\section{$C D$ of NaDNA in Water-Alcohol Mixed Solvents}

$C D$ Spectra of $h D N A$ and $S D N A$. Figures

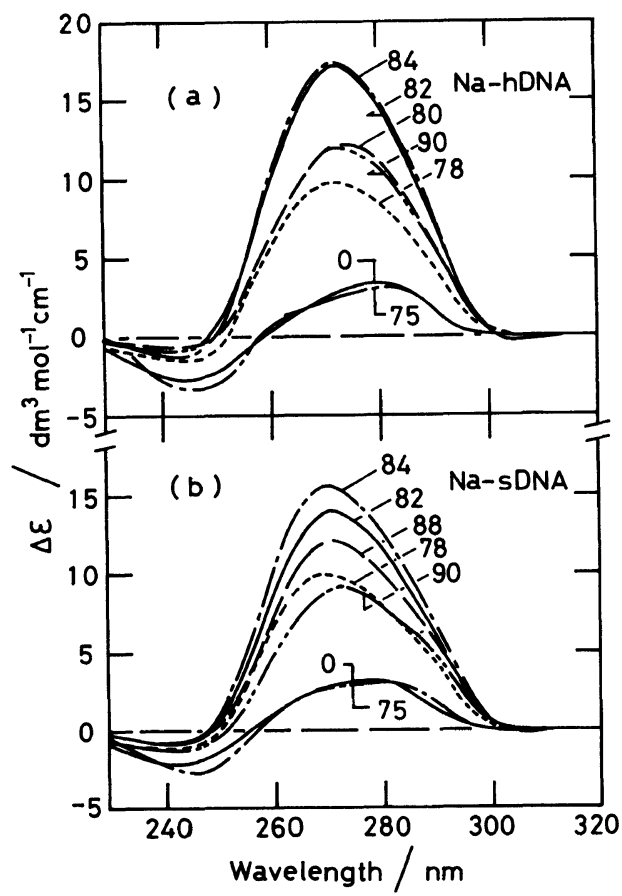

Figure 2. CD spectra of (a) hDNA and (b) sDNA in water-ethanol mixed solvents containing $\mathrm{Na}^{+}$as the counterion at $15^{\circ} \mathrm{C}$. The molar dichroic absorption: $\Delta \varepsilon$ $\left(=\varepsilon_{\mathrm{L}}-\varepsilon_{\mathrm{R}}\right)$. The numerals stand for the ethanol content in vol\%. The ionic strength: $0.4 \times 10^{-3}$.
$2 a$ and $2 b$ show examples of the CD spectra of hDNA and sDNA in water-ethanol mixed solvents containing $\mathrm{Na}^{+}$as the counterion. In the absence of ethanol, the spectrum of hDNA, which has been assigned to a typical B-form conformation, ${ }^{4,16}$ exhibits a positive band $(\Delta \varepsilon \fallingdotseq 3)$ at about $280 \mathrm{~nm}$ and a negative band $(\Delta \varepsilon \fallingdotseq-3)$ at about $245 \mathrm{~nm}$. As reported by Ivanov et al., ${ }^{4}$ the spectral profile remains unaltered up to $75 \%$ ethanol, but then the positive band increases between 75 and $88 \%$. The CD spectra transform from a B-form pattern to another rather nonsymmetric profile, which has been associated with an A-form structure of DNA. ${ }^{1,3}$ A further addition of ethanol to hDNA solution induces a new feature, i.e., the decrease in the intensity of the positive band. ${ }^{22}$

The molecular weight of sDNA is only one-fortieth that of hDNA, or $73 v s .3000 \mathrm{~nm}$ in terms of the contour length; yet, the CD spectra of sDNA and the change with increasing alcohol contents are essentially identical with those of hDNA. This is an important finding, i.e., the $\mathrm{CD}$ pattern is quite insensitive to the backbone flexibility and the continuous winding of the helical DNA chain in the entire alcohol content. The CD spectrum of sDNA also exhibits an A-form pattern with the positive band at $273 \mathrm{~nm}$ in $84 \%$ ethanol solution.

Dependence of CD Bands on Ethanol Content. The CD spectra of hDNA and sDNA exhibit a maximum at $270-280 \mathrm{~nm}$ and a minimum at $240-250 \mathrm{~nm}$. Figure $3 \mathrm{a}$ shows the plots of the molar dichroic absorptions at $273 \mathrm{~nm}$ and $242 \mathrm{~nm}$ vs. the ethanol content. Both $\Delta \varepsilon_{273}$ and $\Delta \varepsilon_{242}$ values remain almost unchanged with ethanol up to $70 \%$, but thereafter $\Delta \varepsilon_{273}$ values increase cooperatively with the increase in the ethanol content, reaching the highest value $(\Delta \varepsilon \fallingdotseq 16)$ at about $84 \%$ ethanol. This cooperative increase of $\Delta \varepsilon_{273}$ in a narrow range of ethanol content $(70-80 \%)$ may be interpreted as due either to the relative arrangement between DNA 


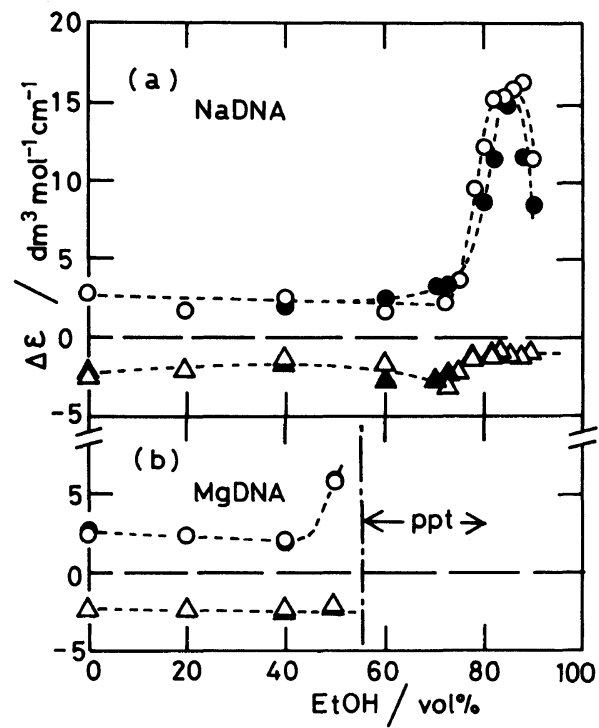

Figure 3. Dependence of molar dichroic absorption, $\Delta \varepsilon$, of (a) NaDNA and (b) MgDNA on ethanol content. Values of $\Delta \varepsilon$ at $273 \mathrm{~nm}(O, O)$ and at $242 \mathrm{~nm}(\triangle, \Delta)$ for NaDNA and at $277 \mathrm{~nm}(\mathrm{O}, 0)$ for MgDNA were evaluated from the spectra in Figures 2 and 6. Open and closed symbols denote hDNA and sDNA, respectively.

base-pairs ${ }^{6,7}$ or to the solvation on the bases. Although CD results are only circumstantial, such a rearrangement or a destruction of the hydrated sheath can possibly induce a structural transition of the DNA helix backbone, e.g., the transition from B- to A-forms. ${ }^{22}$ With a further addition of ethanol $(84-90 \%), \Delta \varepsilon_{273}$ decreases, while $\Delta \varepsilon_{242}$ remains constant. As often reported by previous workers, ${ }^{10,22}$ the appearance of a maximum and a subsequent diminution in $\Delta \varepsilon_{273}$ values is genuine, being difficult to be attributed to precipitation. No precipitates or fibrils were observed for both long (hDNA) and short (sDNA) samples during CD measurements.

Effect of DNA Chain Length on Band Intensities. If the B-form DNA is assumed, the contour lengths of sDNA and hDNA would be 73 and $3000 \mathrm{~nm}$, respectively. The intrinsic viscosities of sDNA and hDNA are 0.87 and $46 \mathrm{dl} \mathrm{g}^{-1}$ in $0.2 \mathrm{M} \mathrm{NaCl}$ at $25^{\circ} \mathrm{C}$, respectively, and the present sDNA molecule is regarded

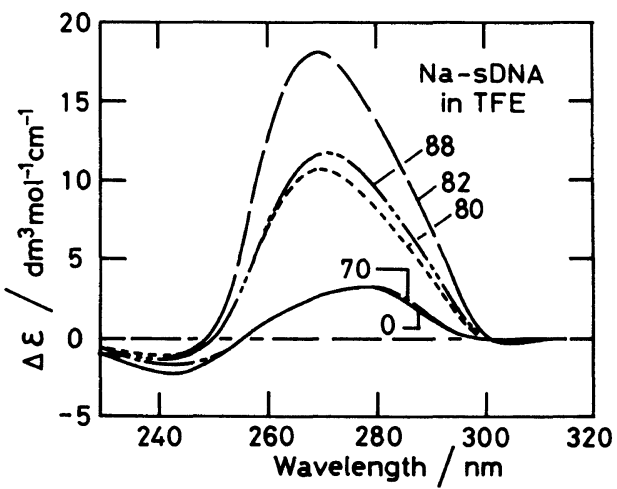

Figure 4. CD spectra of sDNA in water-TFE mixed solvents containing $\mathrm{Na}^{+}$as the counterion at $15^{\circ} \mathrm{C}$. The numerals denote the TFE content in vol\%. The buffer reagent and ionic strength are the same as in Figure 3.

as the rigid rod. ${ }^{30,32}$ If hDNA was also rigid rodlike, the intrinsic viscosity, calculated from Simha's equation, should be about 10 times larger than the experimental value; thus the hDNA molecule is a flexible coil. ${ }^{36}$ In spite of the large difference in the shape and size between sDNA and hDNA, the dependence of $\mathrm{CD}$ bands of sDNA on alcohol contents is very close to that of hDNA; thus the CD spectra are indifferent to the overall conformation. This fact leads to the conclusion that the helical structure remains much the same for sDNA and hDNA and is affected by alcohol in a parallel manner.

Effect of TFE on CD of DNA. Trifluoroethanol, an excellent solvent transparent in the far-UV region, ${ }^{33}$ was examined if it also induces the same or a like spectral change which was observed for ethanol. Figure 4 shows some CD spectra of sDNA in water-TFE mixtures containing $\mathrm{Na}^{+}$as the counterion. In the $0-70 \%$ TFE solutions, the CD spectra of Na-sDNA remain hardly influenced and a further addition of TFE induces the spectral change in a similar manner, as was observed for ethanol; the spectral profile is again assignable to a B-form conformation ( $c f$. Figure $2 b$ ).

Figure 5 shows the dependence of the 


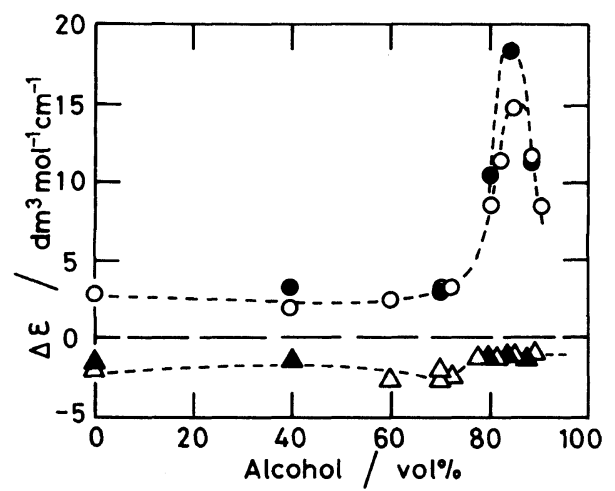

Figure 5. Dependence of molar dichroic absorption, $\Delta \varepsilon$, on alcohol content. Values of $\Delta \varepsilon$ at $273 \mathrm{~nm}(\mathrm{O}, \boldsymbol{O})$ and at $242 \mathrm{~nm}(\triangle, \boldsymbol{\Delta})$ were evaluated from the spectra in Figure 4. Alcohols: TFE (closed symbols); ethanol (open symbols).

positive and negative CD bands of SDNA on the alcohol content on a comparative basis; $\Delta \varepsilon_{273}$ values in TFE or ethanol remain constant $(\Delta \varepsilon \fallingdotseq 3)$ in the $0-70 \%$ alcohol range, cooperatively increasing with a further addition of alcohol. The maximum $\Delta \varepsilon(\fallingdotseq 18)$ is reached at about $82 \%$ TFE and $84 \%$ ethanol, the $\mathrm{CD}$ band decreasing again thereafter. The ability and behavior of TFE to induce the change in CD spectra are identical with those of ethanol. This conclusion suggests that the possible structural transition induced to DNA in the presence of $70-90 \%$ alcohol would also be identical. Hence, the use of TFE as an ultraviolet solvent is recommended for the spectrophotometric and circular dichroic studies of the conformational changes of polynucleotides and nucleic acids.

\section{$C D$ of $M g D N A$ in Water-Ethanol Mixed} Solvents

The CD Spectra of $h D N A$ and $s D N A$. Figure 6 shows some CD spectra of hDNA and sDNA in water-ethanol mixtures containing $\mathrm{Mg}^{2+}$ as the counterion. In the $0-40 \%$ ethanol range, the $\mathrm{CD}$ spectra of $\mathrm{hDNA}$ and sDNA are essentially the same as those assigned to the B-form conformation, closely resembling the spectra of NaDNA ( $c f$. Figure 2). A further addition of ethanol results in an

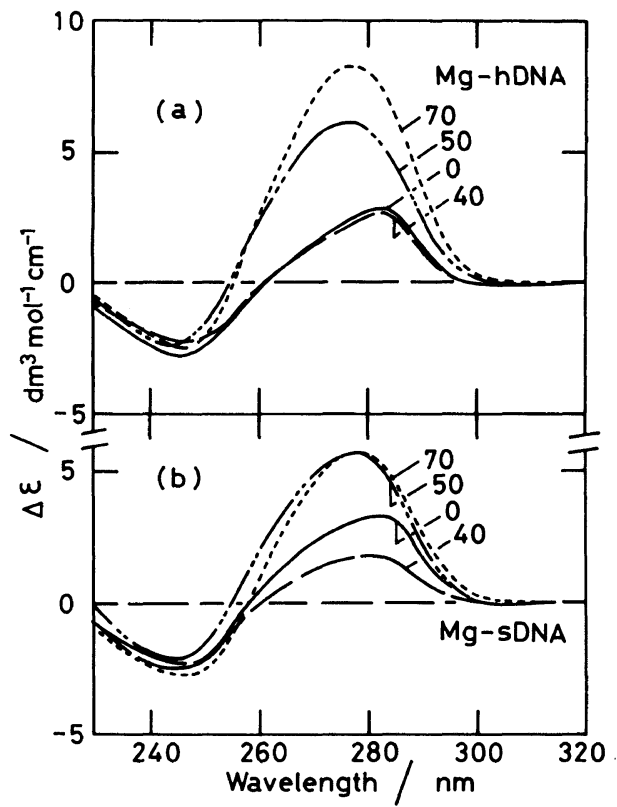

Figure 6. CD spectra of (a) hDNA and (b) sDNA in water-ethanol mixed solvents containing $\mathrm{Mg}^{2+}$ as the counterion at $15^{\circ} \mathrm{C}$. The ionic strength: $0.4 \times 10^{-3}$ with $\mathrm{Mg}\left(\mathrm{CH}_{3} \mathrm{COO}\right)_{2} / \mathrm{CH}_{3} \mathrm{COOH}$. The numerals denote the ethanol content in vol\%. Note that slight precipitates appeared in the solutions of hDNA and SDNA in $70 \%$ ethanol after standing overnight.

increase in the positive band intensity, indicating that some structural changes are induced to hDNA and sDNA. The CD spectral profiles of Mg-hDNA and Mg-sDNA in $50-70 \%$ ethanol are similar to those observed for NaDNA at a higher alcohol content of about $82 \%$ ( $c f$. Figure 2). With respect to the ethanol-induced spectral change, Mg-sDNA behaves identically with $\mathrm{Mg}$ hDNA; again, the molecular weights of sonicated and unsonicated MgDNA samples have no influence on the CD spectra.

The effect of ethanol on the magnitudes of the positive band at $277 \mathrm{~nm}$ and the negative band at $246 \mathrm{~nm}$ are shown in Figure 3b. A comparison of plots shown in Figures $3 \mathrm{a}$ and $3 \mathrm{~b}$ indicates that the lesser amount of ethanol is capable of inducing the CD spectral change for MgDNA. 


\section{CONCLUDING REMARKS}

The condition for $\mathrm{CD}$ spectral change of hDNA and sDNA induced by alcohol is determined. The most important finding is that the induced CD change is independent of the molecular weight or chain length, flexibility or rigidity ( $c f$. Figure 2). Hence, the secondary helical structure of sDNA probably remains the same as that of hDNA, however unknown the structure may be. A UV-transparent TFE also induces the $C D$ spectral change in the same manner as ethanol. Hence, TFE will serve to study an alcohol-induced B-A transition spectrophotometrically in the far-UV region. Contrary to a wide belief, it is actually difficult to identify whichever the secondary structure of DNA is present in aqueous solution, on the basis of the $\mathrm{CD}$ spectrum alone, since the $\mathrm{CD}$ is a short-range optical phenomenon and insensitive to the chain length or the chain flexibility. Thus, it is necessary to clarify simultaneously the overall double-helical chain conformation, the disposition of the base pairs with respect to the helical axis, and the chain length of nonflexible DNA fragments. The transient pulsed electric birefringence ${ }^{37,38}$ and dichroism ${ }^{37}$ techniques may be utilized fully for this purpose. By so doing, therefore, the relationship between the $C D$ spectra and the electrooptical properties can be established to elucidate the precise secondary structure of DNA in solution.

\section{REFERENCES}

1. R. E. Dickerson, H. R. Drew, B. N. Conner, R. M. Wing, A. V. Fratini, and M. L. Kopka, Science, 216, 475 (1982).

2. S. R. Holbrook and S-H. Kim, J. Mol. Biol., 173, 361 (1984).

3. W. Saenger, "Principles of Nucleic Acid Structure," Springer-Verlag, New York, N. Y., 1984.

4. V. I. Ivanov, L. E. Minchenkova, A. K. Schyolkina, and A. I. Poletayev, Biopolymers, 12, 89 (1973).

5. J. C. Girod, W. C. Johnson, Jr., S. K. Huntington, and M. F. Maestre, Biochemistry, 12, 5092 (1973).

6. D. S. Moore and T. E. Wagner, Biopolymers, 12, 201
(1973).

7. D. S. Moore and T. E. Wagner, Biopolymers, 13, 977 (1974).

8. F. M. Pohl, Nature, 260, 365 (1976).

9. C. A. Sprecher and W. C. Johnson, Jr., Biopolymers, 16, 2243 (1977).

10. D. M. Gray, T. N. Taylor, and D. Lang, Biopolymers, 17, 145 (1978).

11. M. H. Zehfus and W. C. Johnson, Jr., Biopolymers, 20, 1589 (1981).

12. R. Huey and S. C. Mohr, Biopolymers, 20, 2533 (1981).

13. J. H. van de Sande, L. P. McIntosh, and T. M. Jovin, EMBO J., 1, 777 (1982).

14. C. A. Sprecher and W. C. Johnson, Jr., Biopolymers, 21, 321 (1982)

15. G. C. Causley and W. C. Johnson, Jr., Biopolymers, 21, 1763 (1982).

16. H. Nara-Inui, H. Akutsu, and Y. Kyogoku, $J$. Biochem. (Tokyo), 98, 629 (1985).

17. S. P. Edmondson and W. C. Johnson, Jr., Biopolymers, 24, 825 (1985).

18. H. T. Steely, Jr., D. M. Gray, D. Lang, and M. F. Maestre, Biopolymers, 25, 91 (1986).

19. D. S. Moore and A. L. Williams, Jr., Biopolymers, 25, 1461 (1986)

20. R. L. Ratliff, J-J. Liu, M. R. Vaughan, and D. M. Gray, Biopolymers, 25, 1735 (1986).

21. J. T. Bokma, W. C. Johnson, Jr., and J. Blok, Biopolymers, 26, 893 (1987).

22. K. Gekko, T. Sakai, and H. Shindo, Polym. J., 20, 751 (1988).

23. S. B. Zimmerman and B. H. Pheiffer, J. Mol. Biol., 135, 1023 (1979).

24. S. M. Lindsay, S. A. Lee, J. W. Powell, T. Weidlich, C. Demarco, G. D. Lewen, and N. J. Tao, Biopolymers, 27, 1015 (1988).

25. J. C. Martin and R. M. Wartell, Biopolymers, 21, 499 (1982).

26. R. Brandes, R. R. Vold, D. R. Kearns, and A. Rupprecht, Biopolymers, 27, 1159 (1988).

27. H. M. Wu, N. Dattagupta, and D. M. Crothers, Proc. Natl. Acad. Sci. U.S.A., 78, 6808 (1981).

28. E. Charney and H. H. Chen, Proc. Natl. Acad. Sci. U.S.A., 84, 1546 (1987)

29. K. Yamaoka, K. Fukudome, and J. Sekiguchi, Abstracts of Papers, 9th International Biophysics Congress, Jerusalem, August 23-28, 1987, p 109.

30. K. Fukudome, K. Yamaoka, K. Nishikori, T. Takahashi, and O. Yamamoto, Polym. J., 18, 71 (1986).

31. K. Fukudome, K. Yamaoka, K. Nishikori, H. Tatehata, and O. Yamamoto, Polym. J., 18, 81 (1986).

32. K. Fukudome, K. Yamaoka, and H. Ochiai, Polym. J., 19, 1385 (1987).

33. V. Rizzo and J. A. Schellman, Biopolymers, 23, 435 (1984). 


\section{K. Fukudome, K. Yamaoka, and M. Yamaguchi}

34. E. Charney and K. Yamaoka, Biochemistry, 21, 834 (1982).

35. M. T. Record, Jr., Biopolymers, 14, 2137 (1975).

36. Z. Kam, N. Borochov, and H. Eisenberg, Biopolymers, 20, 2671 (1981).
37. K. Matsuda and K. Yamaoka, Bull. Chem. Soc. Jpn., 55, 1727 (1982).

38. K. Yamaoka and K. Fukudome, Bull. Chem. Soc. Jpn., 56, 60 (1983). 